\title{
Pain track analysis during gestation using machine learning techniques
}

\author{
Praveen Naik ${ }^{1}$, Vandana Reddy ${ }^{2}$, Ramesha Shettigar ${ }^{3}$ \\ ${ }^{1,2}$ Department of Computer Science and Engineering, CHRIST (Deemed to be University), Bangalore, India \\ ${ }^{3}$ Department of Computer Science and Engineering, NMAM Institute of Technology, Nitte, India
}

\begin{tabular}{l}
\hline \hline Article Info \\
\hline Article history: \\
Received Feb 25, 2020 \\
Revised Dec 16, 2020 \\
Accepted Dec 23, 2020
\end{tabular}

Keywords:

Braxton hicks

Facial recognition

Labor

Support vector machine

\begin{abstract}
During the gestation period women experience Braxton Hicks which is called the false labor, contractions during the second trimester. These contractions are not in regular intervals and also they are often unnoticed. The real labour or the true labour contractions develop late in the third trimester of the gestation usually beyond $36^{\text {th }}$ week (excluding pre-term birth). Some women often fail to identify these pains in the third trimester of the gestation where an efficient facial recognition algorithm along with the support vector machine (SVM) helps them to identify these pains and take optimum care of themselves. The authors in this paper convey a mechanism to identify the pains effectively by creating a database of images pertaining to the pregnant women, her emotional states throughout the pregnancy. Using MATLAB the algorithm of decision tree is implemented and the values obtained from them help us analyze the pain type efficiently.
\end{abstract}

This is an open access article under the CC BY-SA license.

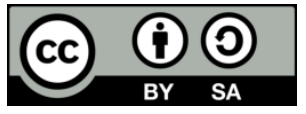

\section{Corresponding Author:}

Praveen Naik

Department of Computer Science and Engineering

Kanmanike, Kumbalgodu Post

Mysore Road, Bangalore-560074, India

Email: praveenrnaik911@gmail.com

\section{INTRODUCTION}

An ordinary pregnancy keeps going 40 weeks from the principal day of the last menstrual period (LMP) to the birth of the infant. It is separated into three phases, called trimesters: first trimester, second trimester, and third trimester. The embryo experiences numerous progressions all through development. Pregnant ladies may encounter certain confusions and side effects as the baby develops. Iron deficiency, urinary tract contamination, and disposition changes may happen. An eager mother may encounter hypertension (preeclampsia), which expands the danger of preterm birth and other potential threats for the baby. Serious morning sickness causes tenacious sickness especially during the initial 12 pregnancy weeks. This may prompt first trimester side effects of weight reduction and lack of hydration, requiring IV liquids and anti-nausea prescription. Pregnant ladies ought to know about the probability of creating gestational diabetes. It causes manifestations like exorbitant thirst and craving and exhaustion. Ladies should put on weight during pregnancy, yet unnecessary weight addition might be related with side effects that put mother and infant in danger. Origination to about the twelfth seven day stretch of pregnancy denotes the principal trimester. The subsequent trimester is weeks 13 to 27 , and the third trimester begins around 28 weeks and goes on until birth. Hormonal changes will influence pretty much every organ in the body. A few indications of early pregnancy in numerous ladies incorporate side effects like cerebral pain, sickness, etc. A few ladies experience a great deal of uneasiness, and others may not feel any whatsoever. Pregnant ladies experience pregnancy contrastingly and regardless of whether they've been pregnant previously. Pregnant ladies may 
feel totally distinctively with each consequent pregnancy. When you enter the second trimester you may think that it is simpler than the first. Your queasiness (morning sickness) and exhaustion may diminish or leave totally. That "baby kicks" will begin to appear as your belly extends with the developing infant. Before the second trimester is over pregnant ladies may even have the option to feel your child move! The third trimester is the last phase of pregnancy. Distresses that began in the subsequent trimester will probably proceed, alongside with some new ones added. As the baby develops and puts more weight pregnant ladies may experience issues in breathing.

During the evolution of human-PC collaboration, researchers normally anticipate that a facial recognition framework should be able to distinguish, examine and process feelings so as to get great impact, for example, discernment, understanding and communicating feelings [1]. If in virtual learning conditions the systems show various articulations in recording, instructing and recognizing by comprehending their training material as per systems' various articulations, and can change their learning strategy. In virtual situations, systems' information can be gotten from a progression of video outlines. Consequently, to accomplish ongoing comprehension of systems' feelings, exactness and time should be adjusted. To improve precision, more video edges are required, expanding calculation of time. Then again, in quest for effectiveness, we would lessen the exactness which means accumulation less inclusive information. Exploratory outcomes from current systems demonstrate that now and again precision is higher, however time spent is likewise high, for example, Potter et al. [2] who utilized decision trees to recognize facial expressions. Different systems have various restrictions; for instance, Gas et al. [3] gave ease outward appearances on a portable stage by simply separating lip highlights, investing less energy yet accomplishing less exactness. To locate the best answer for feeling acknowledgment in learning virtual condition, both precision and effectiveness should be accomplished.

Natural language processing (NLP) is a vast area of computer science that is concerned with the interaction between computers and human language [4]. Within NLP many tasks are-or can be performed as - classification tasks. In classification tasks we are trying to produce a classification function which can give the correlation between a certain 'feature' and a class. This classifier first has to be trained with a training dataset, and then it can be used to actually classify documents. Training means that we have to determine its model parameters. If the set of training examples is chosen correctly, the classifier should predict the class probabilities of the actual documents with a similar accuracy (as the training examples). After construction, such a classifier could for example tell us that document containing the words "Bose-Einstein condensate" should be categorized as a physics article, while documents containing the words "Arbitrage" and "Hedging" should be categorized as a finance article. Another classifier could tell us that mails starting with "Dear Customer/Guest/Sir" (instead of your name) and containing words like "Great opportunity" or "one-time offer" can be classified as spam. Here we can already see two uses of classification models: topic classification and spam filtering. For these purposes a classifiers work quite well and perform better than most trained professionals. A third usage of classifiers is sentiment analysis. Here the purpose is to determine the subjective value of a text-document, i.e. how positive or negative is the content of a text document. Unfortunately, for this purpose these classifiers fail to achieve the same accuracy. This is due to the subtleties of human language; sarcasm, irony, context interpretation, use of slang, cultural differences and the different ways in which opinion can be expressed (subjective vs. comparative, explicit vs. implicit).

\section{LITERATURE REVIEW}

According to the authors of [5-10], Labour pain is one of the most serious issues which has ever assessed and is the one of the reason why ladies wouldn't go for normal deliveries. Considering various variables which influence encountering labor, this examination planned to clarify ladies' encounters of labor during childbirth. This was a subjective phenomenological study. The investigation was made out of 14 ladies in about a month and a half time of regular birth. The information were gathered by meeting. The information were investigated by Colaizzi's seven-organize strategy. In the urge of breaking down the meetings, four primary classes were separated: the nature of delivery pain, the related factors in labor pain, the results of labor pain, and the perception of caseworkers. Evaluating the ladies' encounters can be valuable in giving better care. Positive parts of labor pain must be reinforced and its negative perspectives must be decreased however much as could be expected to make a reasonable vision towards it.

As told in [11-18], the objective is to identify true and false labor. In a planned report during a time of a half year, an aggregate of 178 patients in term (37-41 weeks) counseling in the obstetric unit for uterine compression, were enlisted. Patients were analyzed independently by a birthing assistant and an occupant and isolated into "true labor pain" and "false labor pain". The clinical attributes of true versus false labour in patients were analyzed. ROC bends were created to decide an ideal cervical length and utero-cervical plot for expectation of true labor. The commonness of true work was $57.3 \%$. Patients who were in obvious labor had 
increasingly difficult and progressively visit withdrawals. The "true labor" bunch had shorter cervical length and bigger utero-cervical point. The ideal CL cut-off was $1.4 \mathrm{~mm}$ with a particularity of $73 \%$ (RR 4.3, reasonableness $63 \%$, PPV 14\%, NPV 95\%). The ideal UCA cut off was $123^{\circ}$ (RR 6.7, affectability half, explicitness of $83 \%$, PPV 10\%, NPV 96\%). The best execution was exhibited by consolidated testing, yielding LHR+ that rich 13.

In [19-26], effects of Braxton-Hicks contractions on fetal heart rate variations in normal and growthretarded fetuses were studied. The goal of this investigation was to assess whether Braxton-Hicks contractions prompt changes in fetal pulse in typical and development impeded babies. 110 uncomplicated singleton pregnancies were cross-sectionally examined just as 16 pregnancies muddled by fetal development retreated cases. Fetal pulse inconstancy was dissected by an economically accessible mechanized framework (2CTG Hewlett Packard, Italy) 10 min previously and $10 \mathrm{~min}$ after the Braxton-Hicks compression. All the included fetal pulse tracings satisfied the accompanying criteria: i) nearness of a solitary Braxton-Hicks constriction in the $20 \mathrm{~min}$ considered; ii) nonappearance of fetal pulse decelerations after the compression, and iii) stable fetal pulse standard of conduct in the period broke down. 82 tracings of ordinary fetus were broke down during a functioning fetal pulse design (type B) and the staying 28 during a calm example (type A). In the two examples no noteworthy contrasts were found that lead to long haul abnormality, transient inconstancy, and per-term births were found when the compression. Every one of the tracings of development impeded babies was dissected during the fetal pulse design A. Transient variety and interim list fundamentally diminished during the initial $5 \mathrm{~min}$ after the compression while no critical contrasts were found in the different files researched. The reduction in these lists was altogether progressively set apart in those embryos creating fetal misery inside 7 days. All in all, Braxton-Hicks constrictions incite a huge decline of transient variety and interim record just in development impeded babies. This can be valuable in the early ID of fetal trade-off in such fetus. True labor can be recognized from false labor by impacts, for example, the recurrence and quality of the withdrawals. Prior to "true" labor starts, you may have "false" labor, otherwise called Braxton Hicks contractions. These sporadic uterine contractions are flawlessly ordinary and might begin to happen from your fourth month of pregnancy. They are your body's method for preparing for the "true labor". Braxton Hicks constrictions can be portrayed as fixing in the guts that travel every which way. These compressions don't draw nearer together, don't increment into what extent they last or how regularly they happen and don't feel more grounded after some time. They regularly accompany a difference in position and stop with rest. The manner in which a constriction feels is distinctive for every lady and might feel not quite the same as one pregnancy to the following.

\section{METHODOLOGY}

The proposed system intends to deliver an accurate prediction model for pain analysis during gestation. The model takes two sets of inputs such as features extracted using images and the features extracted using sentiment analysis on the gestation data. The proposed model uses support vector machine (SVM) for sentiment analysis. The images are stored onto a repository and the features of the images are extracted. For sentiment analysis, the gestation datasets are used, that would extract the features of the pain. This extracted data from images and SVM is used to differentiate between false labor pain and true labor pain. Figure 1 demonstrates the overall flow of the proposed system.

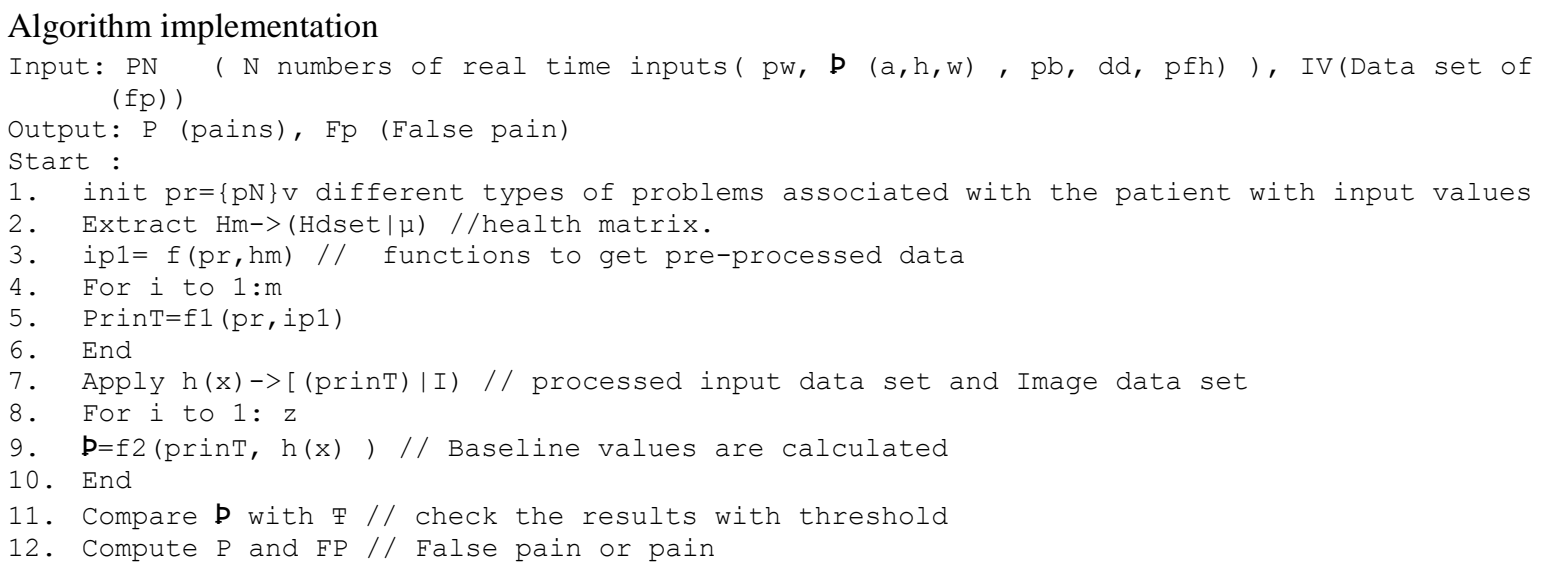

where:

$\mathrm{pr}=$ variable which associates to real time problems in pregnancy

Int J Elec \& Comp Eng, Vol. 11, No. 3, June 2021 : 2128 - 2133 
$\mathrm{pw}=$ variable which associates to pregnancy weeks which is $\mu$

p $(\mathrm{a}, \mathrm{h}, \mathrm{w})=$ age, height and weight

$\mathrm{pb}=$ previous birth record

$\mathrm{dd}=$ due date in pregnancy

$\mathrm{pfh}=$ patient food habit

$\mathrm{fp}=$ dataset of patient face

$\mathrm{IV}=$ Image Vector

$\mathrm{Hm}=$ Health Matrix

Hdset $=$ health data $\mathrm{s}$

ip1 = processed data

$\mathrm{h}(\mathrm{x})=$ processed data with image data set

PrinT $=$ preprocessed data to be given as input

$\mathbf{p}=$ baseline value to be compared with threshold value

$\mathrm{F}=$ threshold value for pain analysis.

The discussion of the proposed algorithm is as follows: the algorithm takes input of PN ( N numbers of real time inputs ( pw, P (a,h,w), pb, dd, pfh) ), IV(Data set of (fp), an image vector) which after processing yields an outcome of true labor pain (P) and false labor pain (FP). The operations of the algorithm can be discussed in below:

- Optimization of 1 st set of inputs

It consists of mathematical variable for all the real time problems evolved in pregnancy stages. There are $\mathrm{n}$ number of variables bounded by $\mathrm{pr}=(\mathrm{pn}) \mathrm{v}$ associated with values $\mathrm{v}($ Line-1), the proposed system can be said to be considered $\mathrm{N}$ number of constrains which associated with $\mu$ constant value which is 36 weeks in pregnancy.

This stages consist of sub process that is extraction of health matrix: this stage is focused on extraction of health quality metrics with $\mu$ and all associated variables values (Line-2). An explicit function $f(x)$ is used to extract the information associated with the range of the health metrics for the inputs (Line -3). Input data are used to process the final values (Line-4 and Line -5). Through $\mathrm{f1}(\mathrm{x})$, face analysis metric is calculated and proceeds as a final input data model (Line-7). Finally the $\mathrm{P}$ were calculated as pain or false pain through $\mathrm{f} 2(\mathrm{x})$ (Line-9).

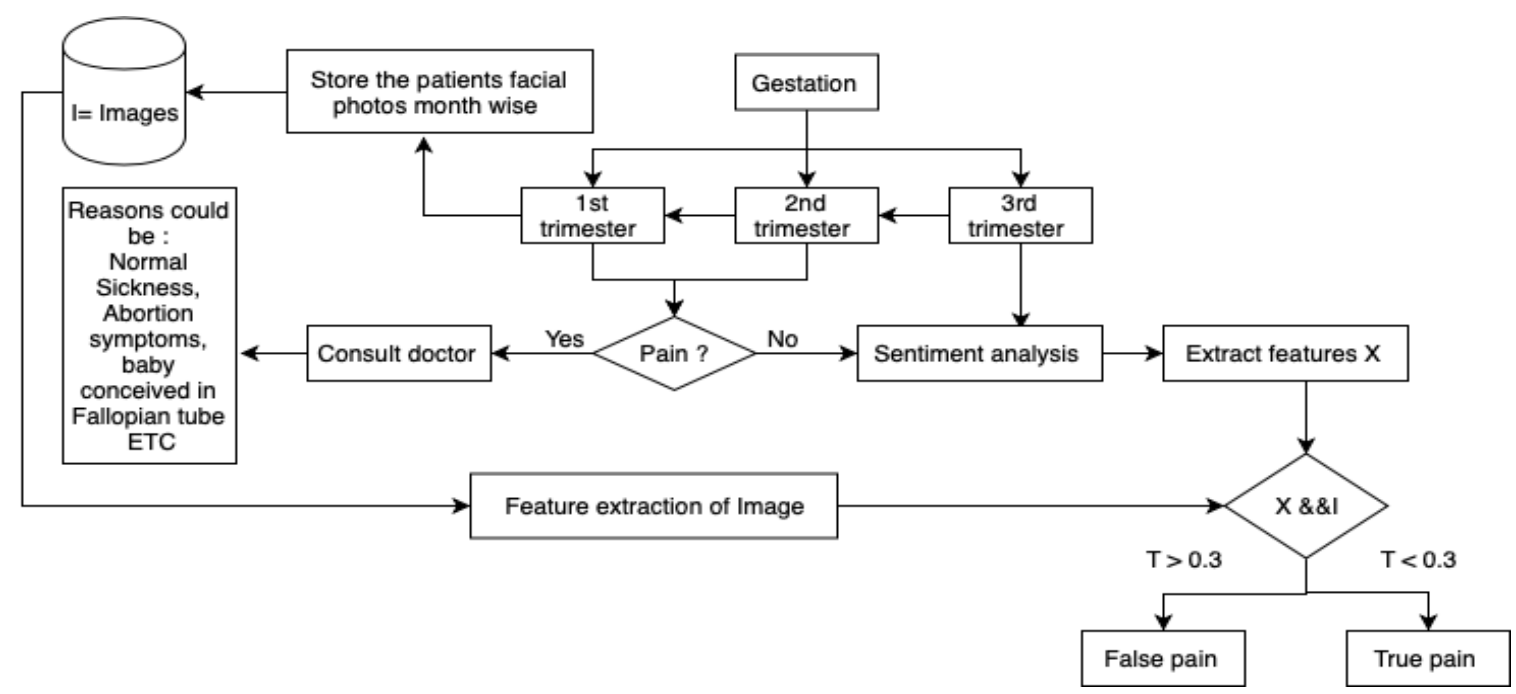

Figure 1. Flow of the proposed system-PTA

\section{RESULTS AND SIMULATION}

The experiment was conducted using MATLAB and python scripting for facial recognition and sentiment analysis where the datasets of the pregnancy was considered for second and third trimester. Figure 2(a) shows the pain track analysis graph (PTA) in the second trimester where the false labor pains are more and the true labor pains are less. Figure 2(b) shows the pain track analysis graph in the third trimester where the false labor pains are less and the true labor pains are more. The comparison of the proposed PTA system is compare with the existing system and the graph for the same is shown in Figure 3. 
- True Pain False Pain

Pain track analysis in second trimester

50

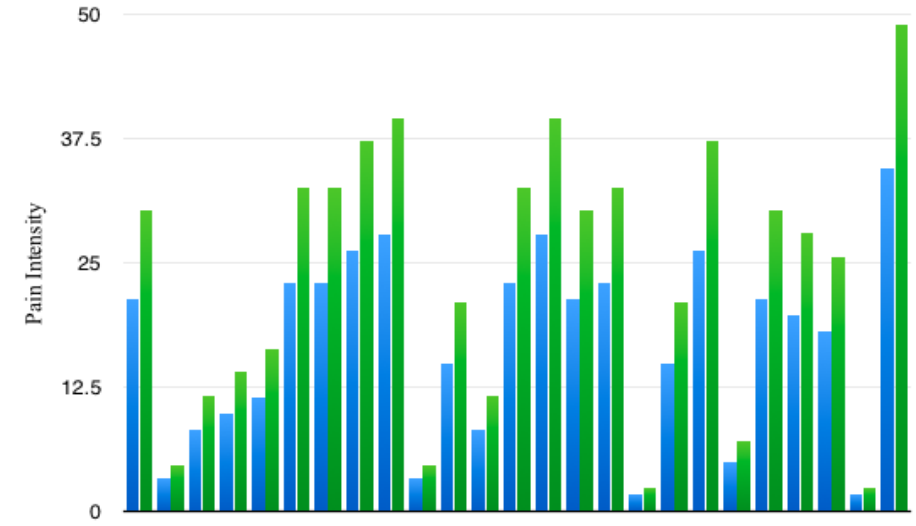

True-False pain Ratio

(a)

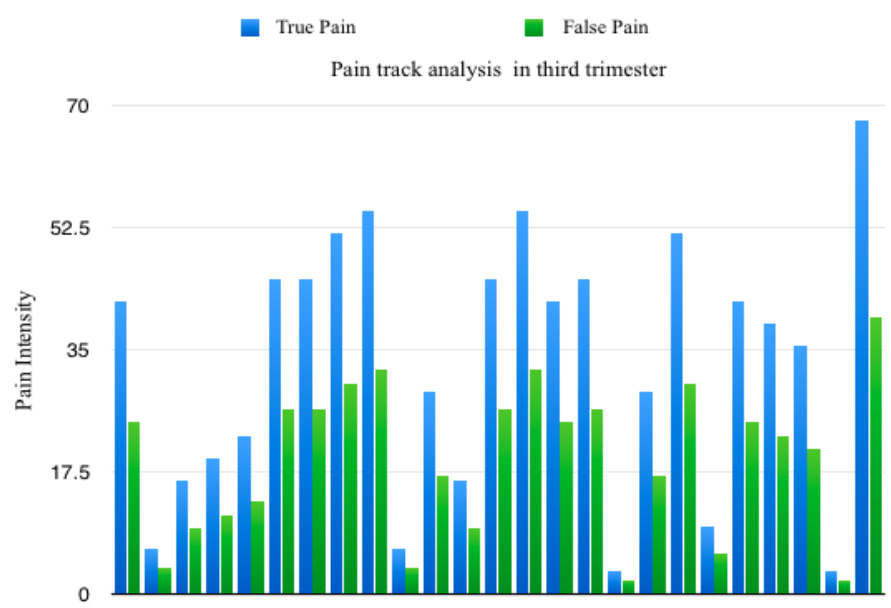

True-False pain Ratio

(b)

Figure 2. Pain track analysis graph; (a) PTA in 2nd trimester, (b) PTA in 3rd trimester

- Existing system prediction $\quad \circ$ Proposed system prediction

70

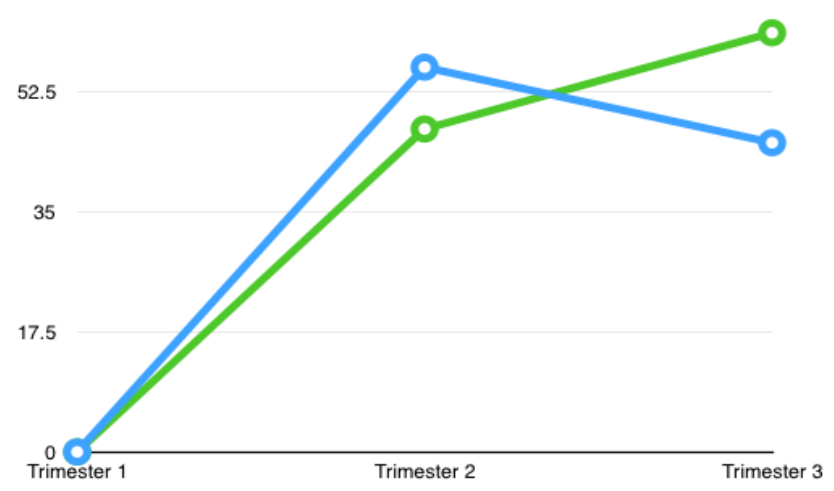

Figure 3. Comparison of proposed and existing system 


\section{CONCLUSION}

The proposed work provides a detailed analysis of the pregnancy phases in trimesters and help understanding the difference between true and false labor pain through sentiment analysis and facial recognition data. This system gives clear pictures about the true pain analysis in $3^{\text {rd }}$ trimester and for analyzing the efficiency of the algorithm the parent data is considered from patient database which consists of 25 patients' data. The work could be further enhanced using deep learning algorithms to improve the efficiency of the system.

\section{REFERENCES}

[1] Yerby M., "Pain in childbearing: key issues in management," 6th ed. Elsevier Health Sciences, 2000.

[2] Potter P.A., Perry A.G., "Basic nursing: a critical thinking approach," 4th ed. Philadelphia: Mosby, 1999.

[3] D. Du Gas B.W., "Introduction to patient care: A comprehensive approach to nursing," 4th ed. Philadelphia: W.B Saunders, pp. 528-530, 1983.

[4] Salehi, K. "Evaluating emotional needs of women who are hospitalized in maternity hospitals of Isfahan University of Medical Sciences on clinical course by midwives," Isfahan University of Medical Sciences, vol. 1, no. 37, 2001.

[5] Olds SB, London ML, Ladewig PA, Davidson MR., "Maternal newborn nursing and women's health care," 7th ed. New Jersey: Prentice Hall, 2003.

[6] Gatchel R.J., dan Turk D.C., "Psychosocial factors in pain: critical perspectives," 1st ed. New York: Guilford Press, 1999.

[7] Niven N., "Health psychology for health care professionals," 3rd Revised ed. Philadelphia: Churchill Livingstone, 1999.

[8] McConnan L., "Measuring a child's pain,” Can Nurse., vol. 88, no. 6, pp. 20-22, 1992.

[9] Karimi M., "Study of life experiences of Thalassemic adolescents," Thesis: Isfahan: Isfahan University of Medical Sciences, 2003.

[10] Cox S., Werner C., Hoffman B., Cunningham F., "Williams Obstetrics," 22nd ed. New York: McGraw-Hill Professional, 2006.

[11] Henry A., and Nand S.L., "Women's antenatal knowledge and plans regarding intrapartum pain management at the Royal Hospital for Women," Aust N Z J Obstet Gynaecol., vol. 44, no. 4, pp. 314-317, 2004.

[12] Beebe K.R., and Humphreys J., "Expectations, perceptions, and management of labor in nulliparas prior to hospitalization," J. Midwifery Women's Health, vol. 51, no. 5, pp. 347-53, 2006.

[13] Melender H.L., "What constitutes a good childbirth? A qualitative study of pregnant Finnish women," Journal of Mid-wifery Women's Health, vol. 51, no. 5, pp. 331-339, 2006.

[14] N. M. Ali Beigi, K. Broumandfar, Parvin Bahadoran, and Heidar Ali Abedi, "Women's experience of pain during childbirth," Iran J Nurs Midwifery Res. 2010 Spring, vol. 15, no. 2, pp. 77-82, 2010.

[15] Bouzid A., et al., "Sonographic landmarks to differentiate "false labor" and "early true labor" as a possible new application of ultrasound in labor ward," J Gynecol Obstet Hum Reprod. 2017, vol. 46, no. 4, pp. 363-366, 2017. doi: 10.1016/j.jogoh.2017.02.012.

[16] Arduini D., Rizzo G., Rinaldo D., Capponi A., Fittipaldi G., Giannini F., Romanini C., "Effects of Braxton-Hicks contractions on fetal heart rate variations in normal and growth-retarded fetuses," Gynecol Obstet Invest, vol. 38, no. 3, pp. 177-82, 1994, doi: 10.1159/000292474.

[17] Callister L.C., et al., "The pain of childbirth: perceptions of culturally diverse women," Pain Manag Nurs, vol. 4, no. 4, pp. 145-54, 2003, doi: 10.1016/S1524-9042(03)00028-6

[18] Andersen L.B., et al., "Risk factors for developing post-traumatic stress disorder following childbirth: a systematic review," Acta Obstet Gynecol Scand, vol. 91, pp. 1261-172, 2012.

[19] Simkin P., and O'Hara MA., "Nonpharmacologic relief of pain during labor: Systematic reviews of five methods," Am J Obstet Gynecol, vol. 186, 2002.

[20] Garthus-N.S., Von Soest T., Vollrath M.E., Eberhard-G.M., "The impact of subjective birth experiences on posttraumatic stress symptoms: A longitudinal study," vol. 16, no. 1, pp. 1-10, 2013, doi: 10.1007/s00737-012-0301-3.

[21] Simkin P., and Ancheta R., "Dysfunctional labour: general considerations," In The Labour Progress Handbook: Early Interventions to Prevent and Treat Dystocia, 3rd edn (Simkin P, Ancheta R eds), Wiley-Blackwell, Oxford, pp. 15-50, 2011.

[22] Carlsson I-M, Ziegert K., SahlbergBlom E., Nissen E., "Maintaining power: women's experiences from labour onset before admittance to maternity ward," Midwifery, vol. 28, no. 1, pp. 86-92, 2012, doi: 10.1016/j.midw.2010.11.011.

[23] Eckert K, Tumbull, MacLennan A., "Immersion in water in thefirst stage of labor: a randomized controlled trial," Birth, vol. 28, pp. 84-93, 2001.

[24] Cammu H, Clasen K, Van Wettere L, Derde M., "To bathe or not to bathe' during the first stage of labor," Acta Obstet GynecolScand, vol. 73, pp. 468-472, 1994.

[25] Rush J., et al., "The effects of whirlpool baths in labor: a randomized,controlled trial," Birth, vol. 23, pp. 136-143, 1996.

[26] Schorn M., McAllister J., Blanco J., "Water immersion and the ef-fect on labor," J Nurse Midwifery, vol. 38, pp. 336-342, 1993 